\title{
La Moralidad del Abogado
}

El año pasado, les hablé de la Magistratura, y me he referido a su gran. deza y a sus servidumbres. Era entonces un testigo que, desde mucho tiempo, la observaba en el ejercicio de su función. He dicho cuanto me impresionaban los esfuerzos que hace, muchas veces en silencio, para juzgar bien. $\mathrm{Si}$ he formulado algunas críticas, los elogios que le he discernido han sobrepasado bastante los reproches y espero haber dejado una impresión reconfortante de nuestra Justicia. Hoy, como para hacer un paraleio, me propongo hablarles de la Abogacia.

Es un tema bastante arriesgado para mi, puesto que pertenezco a esa profesión: si la elogio demasiado, corro el riesgo de que se diga que es algo natural de parte de un abogado y si formulo muchas criticas, se dirá que lo hago llevado por el celo o la amargura. Antes de comenzar a hablar de mi profesion, he dudado y si he aceptado es porque he pensado que $\mathrm{mi}$ antigüedad en su ejercicio me permitia expresarme sin pasión. Dentro de algunos meses, cumpliré cincuenta años en el desempeño de la abogacia. $\mathrm{He}$ tenido que resolver, por mi cuenta, casi todos los prob'emas que pueden prestntarse; he estado mezclado a muchos dramas secretos y he podido darme cuenta de la infinidad de los asuntos que se plantean continuamente a la conciencia del abogado. Muchas veces se presentan con una apariencia compleja, pero en su mayoria se resuelven mediante soluciones de moral elemental.

Todo se resume en una fórmula sencilla: para ser abogado es preciso, ante todo, ser un hombre honrado. El Foro está sometido a una moralidad tanto más estricta que cada uno de sus miembros sólo depende de su propia conciencia. Quien ejerce la profesión debe ejercer, sobre sí mismo y frente a si mismo, una vigilancia permanente. No depende de nadie y es el único juez de sus actos.

$A$ veces, se han hecho distinciones entre el abogado que defiende casos civiles y el que interviene en asuntos penales. Esto constituye un grave error, puesto que los prob'emas son los mismos. Lo que es cierto, es que son más numerosos para el abogado que ejerce ante la jurisdicción criminal, pero los principios no varian. El derecho de la defensa es un derecho natural. No se concibe un inculpado culpable o inocente, un interés lesionado o desconocido, sin que una voz pueda intervenir en su favor. D'Aguesseau 
ha dicho que el abogado es tan antiguo como la Magistratura, y esto es cierto.

El primer abogado ha sido un pariente que ha hecho oir su voz para defender a uno de los suyos; un amigo que ha solicitado justicia para un amigo en desgracia. En sus origenes, fue una asistencia benévola y caritativa. Asi se explican hoy dia ciertas reglas de desinterés que parecen olvidadas y prescritas para quienes no conocen su origen. En aquel tiempo, no se trataba de soluciones jurídicas. El derecho se hailaba aún en la infancia y solamente se trataba de sugerir decisiones de equidad y de buen sentido a jueces, generalmente ancianos experimentados o personas notab'es merecedoras de confianza, escogidas por su sabiduria, su ponderación y la exactitud de sus juicios.

Después, las sociedades han evolucionado. Se han complicado y a la simple noción de equidad que parecia ser, en su origen, el único fundamento de la justicia, se ha superpuesto la noción del derecho. La equidad ofrece la sclución a un caso particular; el derecho establece reglas generales. De. allí conflictos continuos entre el derecho y la equidad cuyo sentido exacto muchos no llegan a comprender. Veamos un ejemplo: está prohibido robar; es una regla general del derecho. Sin embargo, una mujer roba un pan para salvar a su pequeño hijo que muere de hambre. En derecho, hay que condenarla puesto que si se aceptase la justificación del robo por un móvjl particular, no hay ladrón que no hallare un motivo más o menos legitimo para su mala acción. Esto es el derecho. Pero, por otra parte, desde el punto de vista de la equidad, la mujer que roba para salvar a su hijo obedece a una noción que se justifica humanamente. El magistrado se halla frente a este conficto entre el derecho que lo obliga a condenar y la equidad que lo induce a absolver. Deberá conciliar ambas nociones para obtener una solución justa. La buena sentencia es, en efecto, la que concilia el derecho con la equidad, pero entre ambas hay grados y es la conciliación de todos estos principios. muchas veces contradictorios, lo que debe buscar el abogado.

Para juzgar todos los problemas, el hombre prudente o el notable, que juzgaban basados solamente en el buen sentido, no han sido suficientes. Del lado de los jueces, ha sido necesario disponer de hombres conocedores del derecho sin que por ello llegasen a ser inhumanos, y es así como aparecieron los magistrados profesionales conocedores del derecho, sin que la aplicación de sus principios los hiciera inaccesibles. Son de e'los que os hablé el año pasado: hombres bastante aleiados de la ciudad para permanecer alejados de las pasiones, escogidos por la Sociedad para juzgar en su nombre.

Al mismo tiempo nació el Foro.

Para presentarse eficazmente ante los magistrados, era necesario dispo. ner de hombres teniendo - como ellos- conocimientos amplios, resultado de estudios muchas veces extensos. Lo que, en su origen, fue la manifestación de una abnegación aislada y accidental, se ha convertido en una profesión permanente. De esta manera, el abogado, que apareció cuando se organizaba la justicia, se ha convertido en su auxiliar indispensable. 
Es porque, en efecto, el litigante, por más inteligente que sea, necesita ser auxiliado. Solo, se halla desarmado, inquieto, agobiado por el infortunio o temerario, desesperanzado o de una suficiencia deplorable. Se halla obnubi'ado por la pasión, lo que lo hace injusto, no deseando reconocer sus debilidades. Es de buena o mala fé y pronto a enfurecerse. Discute mal, se nutre de ilusiones, o insiste en sus errores. En cuanto al derecho, cuando trata de conocerlo, comete errores imperdonables. De hecho, puede escoger maios argumentos, o presentar argumentos que seducen, para defender una causa mala.

Por todas estas razones, es necesario que haya alguien, al lado de los litigantes para suplir su debi'idad, que los reconforte, que haga comprender su temeridad a los audaces y a los vehementes y los lleve a decir lo que puede justamente decirse, que calme su exasperación, y que devuelva el valor a quienes lo han perdido.

He al'i el papel del abogado cuyo interés personal sólo es secundario. Un viejo abogado que ha publicado memorias ha escrito:

"No existe en la Sociedad un ser débil y sin protección, perseguido por una pasión poderosa o disfrazada; no existe un derecho desconocido. una libertad violada que no llame en su auxilio a un abogado y para el cual un abogado no deje de presentarse, pronto si fuere necesario, a actuar con abnegación en un asunto que jamás es el propio".

Es una tarea difícil que impone deberes imperiosos; son éstos deberes los que voy a estudiar ante ustedes.

En primer lugar, están los deberes frente a uno mismo. Una de las dificultades de la profesión consiste en que sólo puede ejercerse en la soledad. El abogado debe resolver sólo los probiemas que le han sido planteados, $y$ sólo debe responder de sus actos ante él mismo.

Esta es una consideración muchas veces ignorada.

El Pa'acio (de Justicia), si lo habéis visitado, es una hormiguera; cada abogado se halla mezclado a una multitud, pero trabaja solo. La Sala de los Pascs Perdidos, en las horas de afluencia, está repleta de trajes negros. Se ven al'i abogac'os que van, vienen, se detienen a veces, para breves encuentros. Por cortos instantes, un grupo se forma. Si alguien se acerca, se puede notar que hablan de asuntos que en nada se refieren a sus juicios. Si 'as misteriosas hormigas colaboran todas por un interés común, el abogado sólo se ocupa de los asuntos que le han sido encomendados a ignora todo cuanto se relaciona con los demás. El secreto al que está sometido le impide aún comunicar sus dudas. La opinión que puede solicitar a un colega o a un amigo no es jamás sinó sobre algo teórico. No puede indicar cual es la situación exacta, puesto que está sometido al secreto, y esta so'edad exige una probidad particularmente estricta frente a si mismo, puesto que el abogado tiene por censor a su propia conciencia; que nadie sabrá merced a que móviles ha actuado, y que debe primero juzgarse a si mismo y sin indulgencia. 
Una vez que ha jurado, lleva el mismo traje que el Decano, y ya no pu:de contar con nadie para informarle. Lo que debe hacer, tendrá que descubrirlo por sí mismo. Los colegas no le dirán gran cosa. Por cortesia, a veces, lo felicitarán, sin que esto quiera decir que lo admiran. Se le estre chará la mano con un semblante de entusiasmo, lo que no querrá decir que se le atribuya ninguna ciencia, ningún talento. Jamás hallará un colega que le dirá: "Usted ha defendido mal" o aun: "Usted no ha trabajado suficientemente, y esto se ha notado". Del lado de los colegàs, una benevolencia mundana y nada más.

Entonces, ila crítica? No la hay. Existe, es cierto, una crónica judicial, que relata los juicios, pero, raras veces, critica al abogado. Alli también, una tradición de cortesia, basada en servicios reciprocos, impide que se diga la verdad. Jamás se analiza la defensa como la crítica dramática analiza una obra, discutiendo el plan, el valor de los argumentos y la corrección del idioma. La mayor parte del tiempo, son elogios discretos de los que nada se puede retener.

Asi aparece la soledad del abogado. Se halla reducido a si mismo para apreciar el limite de sus medios y cuando, joven. llega al Palacio (de Justicia), después de haber prestado juramento, tiene, s'n embargo, que aprenderlo todo. Licenciado en Derecho, no sabe gran cosa. Se le ha enseñado los rudimentos del Derecho, pero, aún si ha sido un buen alumno, ignora todavia mucho. Desde hace aigunos años, se ha agregado a la licencia un año suplementario de estudios para obtener un certificado de aptitud profesional. Se 'e enseña algo de práctica. Pero, hay algo que jamás se le enseña, es la retórica. En el liceo, en los colegios no se habla de ella. Y se llega a esta s'tuación paradoxal que en una profesión donde el saber hablar es esencial, no se exige un conocimiento de la manera como debe expresarse para exponer su pensamiento.

Frente a sí mismo, no tiene el derecho de quedarse a'li. El aprendizaje puede ser largo y hay que desconfiar de la facilidad. La facilidad es un gran escollo, ya que purde llegar a producir verdaderos habladores, pero no ora. dores. Mediante elia se podrá deslumbrar a la masa, pero se seguirá siendo ineficaz.

Por lo demás, fuera del arte oratorio, que sirve a poner en ev'dencia las ideas, conviene adquirir una gama de conocimientos cuya cantidad es iimitada. Todos los conflictos, sean estos públicos o privados, llegan a la Corte y el abogado debe estar listo para tratar todos los asuntos. Las cuestiones, lás más imprevistas, pueden presentarse de un momento a otro; muchas veces hay que resolverlas urgentemente y el abogado debe estar en condiciones de tomar resoluciones que comprometen al cliente y que pueden ejercer su influencia sobre todo el juicio. Un error del primer instante puede comprometer, de manera irreparable, el porvenir. Sin embargo, ninguin hombre. puecie ser universal, pero el abogado debe tratar de serlo. En el siglo XVL el jurisconsu'to La Roche-Flavin escribia: 
"Hesiodo dice que el arado con el que se trabaja la tierra debe tener cien piezas de madera. Quien quiera ser buren abogado debe proveerse de cien instrumentos. Fuera del Derecho, que constituye el fundamento de su ciencia, tendrá que haber estudiado a la perfección la gramática, la retórica. la dialéctica, la ciencia de las costumbres, la politica, la historia..." y !a lista que sigue es interminable.

No hay que creer que se escapa a estas obligaciones especiallzándose. Es raro que alguien pueda deliberadamente especializarse en una rama del derecho. Es, muchas veces, la casualidad de determinada clientela que especializa al abogado. Un juicio en el que ha triunfado que le trae otros. $Y$, aún asi, la especialización no es jamás tan estrecha que no sea a veces ne. cesario salir de ella para emprender otros rumbos. No se puede permanecer siendo el hombre de un solo tema.

Es asi como, en primer lugar, hay que juzgarse uno mismo y mostrarse severo para no atreverse a emprender más de lo que se pueda realizar. Esta disciplina personal se extiende hasta el comportamiento privado. Sin duda, la vida privada es impenetrable, pero en la medida en que sus manifestaciones no permiten a la opinión juzgar mal al hombre. Si su vida es desordenada, el valor que se otorga a la moralidad se desvanece y la dignidad profesional sufre un grave impacto. El hombre público y el hombre privado deben tener igual honorabilidad. La Roche-Flavin decia:

"Es menester que los abogados convenzan que son verdaderos hombres de bien. Su esfuerzo para convencer seria vano si su vida contradijera y.refutara sus palabras".

La verdad es que el crédito de un abogado descansa en gran parte sobre el valor moral que se la atribuye. Es lo que ha sido muy bien expresado por un magistrado del siglo XIX ${ }^{\circ}$. Bellärt, cuando decia, durante una audiencia solemne:

"No es suficiente, en la Orden de los Abogados, no faltar a la probidad; es preciso, además, ser hombre irreprochable y ser alli modelo de virtudes pubiicas y privadas".

La fórmula es algo pomposa; lleva el signo de su tiempo, pero la idea sigue siendo verdadera.

Conocerse, juzgarse, conservar el dominio de si mismo, ser de una gran honradez, no deben, sin embargo convertir al hombre en un ser insensible. Hay que seguir siendo humano para socorrer a los desesperados y sostener moralmente a lus desgraciados. Participar en los infortunios de otro, es en cierta forma socorrerlo y apropiarse de un arma para defenderlo. La insensibilidad es inhumana: no se tiene el derecho de presentarse en el Foro con un corazón egoista. Es solamente cuando ha aprendido la noción de los deberes que tiene frente a él mismo que el abogado puede juzgarse verdaderamente digno de ejercer la profesión. Estar seguro de su honradez, cons- 
ciente de sus ignorancias, tratar de mejorar sus conocimientos mediante un trabajo constante, imponen servidumbres necesarias sin cuya observancia no se es digno de ser abogado.

Si un practicante me preguntase cual es la condición más esencial para el ejercicio de la profesión, le contestaria sin vacilar que es la sinceridad. El problema de la sinceridad es uno de los que dá lugar a más controversias. En el público, no se cree en ella. Por el hecho que dos abogados se enfrentan y sostienen tesis contradictorias con igual vehemencia, mucha gente piensa que uno de los dos es necesariamente de mala fé. Sin embargo, la sinceridad es una cualidad moral indispensable, sin la cual no hay hombre honrado.

¿Qué es, por consiguiente, la honradez? Es creer en lq que se dice, en el instante en que se dice.

Esto no quiere decir que lo que se cree es necesariamente la verdad. Se tiene el derecho de equivocarse. Los hombres pueden equivocarse, pero siempre deben ser de buena fé. Sostener algo que no se cree o que se sabe ser falso, es faltar a la honradez y no merecer confianza.

¿Cómo conciliar entonces la sinceridad de dos abogados que sostienen, con igual vehemencia, opiniones opuestas? El problema parece complejo. pero su complejidad es sólo aparente.

Lo que se debe saber es que raramente el cliente dice a su abogado toda la verdad sobre las circunstancias que rodean su asunto. Es una vieja pregunta que se ha hecho cien veces a todos los abogados cuando se les interroga sobre su profesión: ¿Cómo puede usted sostener la inocencia de un hombre, sabiendo que es culpable?

La gente se imagina que el abogado es un confesor y se equivoca. Antes de tratar de engañar a su juez, el inculpado comienza por engañar a su abogado. $\mathrm{Ha}$ adoptado un sistema que representa cierta verdad que estima favorable a su interés. Mezcla algo de verdad con algo de falsedad. Procede a veces por abstención, disimulando una circunstancia o algún hecho que lo molesta. Pareciera que temiera debilitar la convicción de su defensor al decirle la verdad. Sabiendo que su defensor es honrado, no le dirá más de lo que dirá al juez a quieri tratará de engañar. No dirá sino lo que cree necesario para hacer de él un cómplice de buena fé. Sin embargo sigue repitiéndo'e que le considera como un confesor.

Cada profesión tiene su anecdotario. En el Palacio (de Justicia) se relata una vieja historia clásica que ilustra. de manera maravillosa, lo que acabo de exponer. Se cuenta que un abogado, feliz de haber ganado un juicio, telegrafió a su cliente: "El derecho ha triunfado". Sin dudar sobre el sentido del fallo, el cliente contestó en el acto: "Apele".

El caso del cliente que hace a su abogado una confidencia grave y que le pide que arregle las cosas para engañar a la justicia es de una excepcjonal rareza. En cuanto a mi, en el curso de una larga carrera, sólo lo he hallado dos vaces. No he dudado sobre la conducta que debia seguir. No pudiendo más actuar con sinceridad, rogué a mi cliente que cambiara 
de actitud y le aconsejé que dijera al juez lo que me había dicho, o, en casc contrario, que escogiera otro abogado.

Algunos piensan que, en este caso, es posible hacer abstracción de lo que se sabe, limitarse al estudio del expediente $y$, si se descubre la manera de defender la duda, hacer valer sus razones. Por mi parte, creo que se trata de una transacción de conciencia inadmisible. Sólo se puede defender la duda cuando uno mismo duda.

Puede suceder, sin embargo, que, a través de la mentira, se descubra la verdad. Debe entonces hacerse ver al cliente que lo que sostiene es inverosimil, que su juicio puede defenderse bajos ciertos aspectos sin alterar la verdad, $y$, si insiste en su actitud, es preciso dejarlo.

Muchas veces no se piensa que un asunto puede ser defendido de mil maneras y que, aún malo, puede presentar aspectos que pueden defenderse con sinceridad; el derecho es controvertido y el hecho se presenta, tal como se conoce, con aspectos inciertos.

Es por eso que una regla fundamental consiste, antes de aceptar la defensa de un juicio, en juzgarse uno mismo. Es una fórmula tradicional que conviene siempre respetar. Un Decano del Foro de París trató antaño de refutarla. Escribió:

"El abogado que se hace él mismo el primer juez de la causa, es una vieja fórmula que ha seducido a nuestra juventud. Es muy bella, muy noble, pero muy falsa y peligrosa. Por lo tanto, cuidémosnos. Si, en efecto, podemos juzgar antes que el juez, ya estamos convencidos -a no ser que sea el juez él mismo- de incompetencia o de falta de sinceridad cada vez que perdemos un juicio. $Y$ hé alli justificadas al mismo tiempo todas las acusaciones populares".

Hablar asi es enunciar un sofisma. En la evidencia, el abogado no juzga como el magistrado que habrá oido a ambas partes y conocido los argumentos más completos del problema. No puede tampoco conocer la verdad judicial -icuán relativa desde luego! - que será determinada por el Juez al finalizar el Juicio. Pero, es indispensable que, con los medios de que dispone, examine, si esto es posible en conciencia, que le es dable defender con sinceridad los intereses que se le encomienda. Ya, Cicerón habia escrito en su "Pro oratore":

"Tengo la costumbre de conocer el asunto por intermed'o de mi cliente, él mismo; de estar solo con él a fin de que hable libremente; de desempeñar el papel de su parte con el fin de que me instruya completamente; de darle todo el tiempo necesario para que se explique. Después, cuando todo ha sido dicho, me coloco, sin ninguna prevención, en la posición de su adversario y en la del juez".

Si se supiera que un abogado está dispuesto a defender cualquier cosa, perderia todo crédito. ¿No es esta la prueba de que la sinceridad es una cualidad esencial? Por eso, no me parece concebible que un abogado acepte 
un asunto sin haber pesado el pro y el contra y sin haber apreciado si puede, con sinceridad, aceptar el encargo. Sin duda, no puede juzgarla sinó con lo que tiene, es decir sin disponer de todos los argumentos del problema, pero, por lo menos, aún si su convicción es errónea, es honrada si cree en ella.

La opinión que tiene el abogado sobre el asunto que se le propone no es necesariamente la verdad, pero se halla en paz con su conciencia, si cree que la causa es justa, si cree que lo que argumentará es la verdad y si cree que lo que defenderá es honorab'e. Nadie puede obligar a defender una causa con argumentos que no se aprueban.

Por lo demás, es raro que una causa, aún mala, no presente alguna circunstancia honradamente defendible, si se tiene en cuenta la complejidad de los asuntos, la multiplicidad de los medios y la relatividad de la verdad. Defender no es necesariamente lograr la absolución o ganar un juicio; es, sobre todo, contribuir a obtener una so'ución que se cree juridicamente y humanamente justa. La aceptación de una causa no debe depender del interés personal del defensor, ya sea que este interés sea pecuniario - publicitario. Antes de ejercer la profesión para él, el abogado la ejerce para los demás.

Hay que agregar que la sinceridad ileva consigo una recompensa que es el crédito. Un juez escucha con más interés al abogado de quien no puede esperar alguna sorpresa. Lo esencial consiste en no mentir a los demás después de haber mentido a uno mismo, por cualquier causa que sea.

Sin embargo, la sinceridad seria aún muy poca cosa si el abogado no gozara de suficiente independencia para poder expresarse libremente.

Si es un auxiliar de la Justicia, es porque contribuye a hacer rendir por los jueces una sentencia justa, pero no forma parte del personal de la Justicia. No tiene que recibir instrucciones ni órdenes de nadie y es menester que goce de una libertad completa para poder llegar a las conclusiones y desempeñarse como lo entiende. En Roma, un esclavo no podía ser abogado. He hallado, en un antiguo texto, una fórmula magnifica, que debería servir de epigrafe a todas las obras que se refieren a la profesión de abogado:

"Libre de todas las trabas que cautivan a los otros hombres, muy orgulloso para tener protecores, muy oscuro para tener protegidos, sin esclavo y sin dueño, el abogado sería el hombre en su dignidad original, si tal hombre pudiera existir".

Fórmula tal vez algo so'emne para nuestra época, pero que resume bien lo que debe ser la independencia. La libertad del defensor debe ser considerada como una noción de orden público, pero que impone grandes servidumbres. El abogado debe defenderse de la intriga y de los compromisos a los que se trata de llevarlo y sin decirselo muchas veces. Debe permanecer alejado de las pasiones, huir de las sospechas y no tener que rendir cuentas a nadie, salvo a él mismo, es decir que es frente a él mismo que debe en primer lugar ser independiente. 
El abogado no debe ponerse en el caso de hacer discutir su conducta. De alli, incompatibilidades absolutas con actividades que son, desde luego. muy honorables. No puede ejercer ningún comercio o negocio que puedan llevarlo a aceptar obligaciones que pudieran ser objeto de litigios judiciales por ejemplo de quiebra. No le es permitido aceptar un empleo con sueldo, debido a la subordinación que es su consecuencia. No le es permitido administrar los asuntos de otro, ya que el mandato obliga a rendir cuentas. Estas prohibiciones no le son impuestas por estas actividades muy estimables, sino solamente para que jamás, aún por una sospecha injusta, su delicadeza pueda ponerse en duda.

Desde luego, ciertas tendencias, desde algunos años, han llevado a ampliar la actividad de los abogados. La aceptación de ciertos mandatos judiciales les ha sido permitida. Aún, el manejo de ciertos fondos les son permitidos, péro sz puede decir que el principio es discutible, puesto que exige el control de la Orden (de Abogados) y que el hombre absolutamente independiente no tiene que someterse al control, fuera de los casos en que comete faltas profesionales.

La soledad del abogado acompaña su independencia, y nada debe realizar cuando puede ser discutido, si quiere seguir siendo indiscutible.

$\mathrm{La}$ independencia que el defensor debe tener frente a él mismo, debe también adquirirla frente a terceros, la Magistratura y el Poder.

Una regla antigua quiere que no salga de su estudio. Es sabia. El abobado que permanece en su estudio se halla al abrigo de promiscuidades o de encuentros molestos. Otra regla ordena que nunca tenga relación directa con su adversario, lo que evita que pueda acusársele de colusión, y debe evitar las familiaridades que puedan permitir que se le acuse de complacencia. Respetando estas obligaciones, conserva una libertad contra la cual nadie puede atentar.

Esta libertad aparece como particularmente fundamental cuando la de. fensa se halla en conflicto con el Poder, especialmente en materia politica. El Poder es poderoso y, mezclado a pasiones fuertes, el defensor se encuentra frente a obstáculos que pueden exigir mucho valor para enfrentarlos. El valor en este caso es solamente la manifestación de la firmeza de la convicción.

A los gobiernos no les gusta la independencia de los abogados. Durante la Revolución fue suprimida su Orden. Cuando, bajo el Primer Imperio, se pensó en reconstituirla. Cambacerés propuso al Emperador un decreto que la restablecía más o menos tal como existia durante el Antiguo Régimen. Después de leerlo, Napoleón escribió, en 1810, a su Ministro:

"Este decreto es absurdo. No deja ninguna acción, ninguna influencia sobre los abogados. Son facciosos, fabricantes de crimen y traición. Mientras tenga la espada al lado, jamás firmaré tal decreto. Deseo que se pueda cortar la lengua a un abogado cuando la utiliza contra el Gobierno" 
Sin embargo, es tan imperioso el principio de la independencia, que, seis meses más tarde, el Emperador firmaba el decreto. El ejercicio de la profesión no se concibe sin la libertad de expresión. Ninguna consideración puede impedir que el abogado diga lo que piensa.

La única dificultad consiste en ser objetivo y permancer alejado de las pasiones, escapar a la tentación de aprovechar la ocasión para sostener sus propias opiniones, como si. en lugar del juicio del cliente, el abogado se considerara como personalmente en causa, y no hacer obra de proselitismo. Se defiende, nó para si, sinó para el cliente, y el Foro nó es una tribuna destinada a permitir que el abogado haga gala de sus propias pasiones. El cliente tiene razones de conciencia que lo han inducido a actuar; hay que exponerlas objetivamente y no tratar de convertirse uno mismo en parte.

Dicho esto, nada puede trabar la libertad. Es lo que ha sido muy bien destacado por una resolución del Consejo de la Orden de Lieja que, en vista de un reclamo por un pretendido atentado al respeto debido al Poder, contestó:

"El abogado goza, como todo ciudadano, del derecho de control y si su conciencia le hace un deber de censurar los actos de los Poderes Públicos -especialmente si uno u otro representante de la autoridad le parece haber faltado a las obligaciones de su función- nada se opone a que llame sobre esto la atención de la opinión pública. El Foro, orgu'loso de su independencia ha, en todo tiempo, reinvindicado a este respeto una libertad absoluta de apreciación y de critica. La firmeza en la expresión del pensamiento no es obstáculo a la moderación en los términos".

Es porque, en efecto, la independencia tiene como contra-parte la moderación en la expresión y el decir. Sé es tanto más fuerte cuando más se conserva el dominio sobre si mismo y que se opone una firmeza desprecia. tiva hacia la ofensa, la injuria, y la invectiva. Alli donde el abogado, arrastrado por la pasión, no podria contenerse comprometiendo su propia causa, la presencia del defensor que opone una tranquila firmeza se justifica. El es quien hace, imperturbable, valer los medios, defiende $y$, en caso necesario, ataca, pero sin perder una moderación en la forma, sin la que no hay discusión razonable. El abogado goza de una inmunidad que lo protege, pero con la condición de no transformarse en un insultante a sueldo, D'Aguesseau ha dicho de éste:

“Arbitrio de todas las familias, juez voluntario de los más célebres diferendos, debeis temer de haceros indigno conservando aún esa exagerada vehemencia, ese espiritu de partido, esa prevención, que solo pue. den ser dañinos para la defensa de vuestro cliente"..

La firmeza no es la violencia y se logra aún más autoridad cuando se opone a las pasiones, que se contienen mal, una firmeza tranquiia, resuelta y algo altanera. 
Frante a su propio cliente, el abogado no debe ser menos independiente. No debe recibir instrucciones y es libre de escoger su manera de actuar. Instrucciones imperativas de su parte serian inaceptables.

El abogado estudia su expediente y escoge sus medios de defensa. Hară, desde luego, conocer sus intenciones a su cliente y deberá obtener su consentimiento, pero, si este pretende imponerle medios que no le convienen, deberá dejarlo. Si aceptara proceder de otra manera que la que le parece razonable y legitima, dejaria de ser sincero, se convertiria en esa conciencia de alquiler, a la que se refiere Dostoievsky. y aceptaria un papel subal. terno, incompatible con su carácter.

De esta manera, la independencia que garantiza la sinceridad es el fundamento mismo de la profesión.

Es solamente cuando el abogado ha comprendido bien que no depende de. nadie que llega a ser lo suficientemente libre para escapar a toda intimidación; cuando se comprende que su interés personal no cuenta, puede levar el amor a su profesión hasta el punto de tener, hacia él mismo, una despreocupación imprudente; llega entonces a ser insospechable.

He alli las obligaciones morales del abogado, muchas veces desconocidas del público y del mismo cliente. Llevan consigo grandes servidumbres, pero confieren cierta grandeza. Exigen un trabajo oscuro y constante y necesitan una labor desconocida y muchas veces ingrata. Cada asunto exige un esfuerzo particular y nada es más falso que creer que la facilidad suple al trabajo. Lo que se considera facilidad no es muchas veces sino la conclusión de un trabajo agotador durante el cual no se debe jamás olvidar que no se trabaja para si y que la mejor recompensa es menos el provecho personal, que la estimación que le otorga quien le ha entregado su confianza.

Cada asunto hace nacer escrúpulos. Hay que escuchar con paciencia, consu'tar, aconsejar, resolver con la angustia permanente que produce el sentimiento que se dispone de la suerte, de la vida, de la fortuna y del honor de otro. Una resolución tomada tiene muchas veces graves consecuencias y puede ser determinante más tarde. Hay que hacer lo imposible para no equivocarse $y$, al mismo tiempo que se aconseja, seguir siendo humano.

La profesión de abogado lleva consigo un aspecto caritativo, que no se tiene el derecho de olvidar. Son muchas veces miserias e infortunios los que llegan hasta el abogado. Lo más dificil es conservar una justa medida y permanecer sensible ante los dolorosos problemas cuyos secretos muchas veces nadie conoce. ¿Cuántas confidencias dolorosas hay que escuchar, a cuantos hay que consolar, cuantas tristezas e inquietudes hay que calmar! Pero entre tantos dramas intimos, el abogado se halla investido de una misión magnifica. Desempeña una profesión donde quien la ejerce está abàndonado a si mismo, rodeado de solicitudes, de tentaciones y de peligros; una profesión que exige una libertad que no tiene por limites sinó las fronteras de su conciencia: una profesión que plantea problemas que solo él conoce. que debe resolver sin hablar de ellos a nadie y de los cuales solo rinde 
cuentas a él mismo. D'Aguesseau, que siempre tenemos que mencionar, ha dicho de ella:

"Exenta de toda clase de servidumbres, esta profesión alcanza la mayor elevación sin perder ninguno de los derechos de su primera libertad. Desdeñando todos los ornamentos inútiles de la naturaleza, puede convertir al hombre en noble sin nacimiento, rico sin bienes, elevado sin dignidades, feliz sin el auxilio de la fortuna".

Sin embargo, solo se puede ejercer esta profesión si se cree en ella y si se la quiere. El amor de su estado es un gran secreto. Hay que compadecer a quienes no ven en ella sinó un oficio que les permite vivir. Hay que amarla porque se tiene el sentimiento de ser útil; hay que esforzarse por comprender su importancia, dedicándose por entero a cada. asunto como si fuera el único que se deba atender.

El gran escollo es la lasitud. Cuando era joven "stagiaire", un viejo redactor judicial, testigo del esfuerzo que habia realizado para hacer triunfar una causa, me dijo: "Le he escuchado. Se inicia usted bien. Conserve su entusiasmo, pero, créame, el día en que su profesión llegue a fastidiarle. déjela".

Era un hombre de bien y jamás olvidé su consejo. Desde cincuenta años, jamás he hallado la lasitud y es porque jamás he dejado de amar mi profesión que sigo ejerciéndola.

Maurice Garçon de la Academia Francesa

NOTA. - Agradecemos muy especialmente al eminente autor, Maitre Maurtce Garçon, quien nos ha autorizado muy gentilmente a publicar el texto que presede, traducido del francés. También agradecemos al Sr. Francis Ambrière, quien nos otorgó su conformidad como Director de la Revista "Les Arnales" que lo publicó en su número de noviembre de 1961. (J. K. M.). 